\title{
Input AC Voltage Sensorless Control Scheme for a Three-Phase PWM Rectifier in Wind Power Generation System
}

\author{
YanJun Wu *
}

\begin{abstract}
In this paper, a sensorless control scheme for a three-phase bi-directional voltage-type PWM rectifier in wind power generation system that operates without the input AC voltage sensors (generator side) is described. The basic principles and classification of the PWM rectifier are analyzed, and then the three-phase mathematical model of the input AC voltage sensorless PWM rectifier control system is established. The proposed scheme has been developed in order to lower the cost of the three-phase PWM rectifier but still achieve excellent output voltage regulation, limited current harmonic content, and unity input power factor.
\end{abstract}

Keywords: Three-phase PWM rectifier, Wind power generation system, Input AC source voltage sensorless control, Space vector modulation, Power factor correction, DC voltage control

\section{Introduction}

Three-phase PWM rectifiers, which have more and more widespread applications, are a hot research area because of their ability for bi-directional energy flow, as well as their ability to produce arbitrary AC current waveforms and power factor. However, there are still some disadvantages in three-phase PWM rectifier control, such as high harmonic distortion that exists in control lag caused by the massive calculations required for the sensor error [1].

According to the inner loop control object, PWM rectifier control methods can be subdivided into four groups. They are Voltage Orientation Control (VOC) [1], Virtual Flux Orientation Control (VFOC), Voltage Orientation Direct Power Control (VO-DPC), and Virtual Flux Orientation Direct Power Control (VFO-DPC) [2]. Among these methods, VOC is the most traditional control scheme and has been fully researched and is the method that we used in this paper. VOC achieves unity power factor operation by controlling the $\mathrm{AC}$ side current vector which rotates with AC side voltage vector synchronously. Switching signals of each bridge arm can be produced by Sinusoidal PWM (SPWM) or Space Vector PWM (SVPWM).

In this paper, we propose the input AC source voltage (generator side) sensorless control for PWM rectifier in

* Dept. of Electrical Engineering, Chonnam National University,

Gwang-ju, Korea. (nijiashaoye@naver.com)

Received 31 July 2012; Accepted 8 Novemger 2012 wind power generation system. To produce the PWM switching signals, SVPWM is selected and then PSIM simulation is performed. As a result, it could confirms that $\mathrm{AC}$ source voltages are estimated by detection of just the AC source currents, and the input power factor of the PWM rectifier tracks to unity power factor. Also, we found that the output DC voltage of the PWM rectifier shows the ability of tracking the different references within a fast setting time and with little oscillation.

\section{The Proposed Method}

Three-phase PWM rectifier is a product of the development of power electronics and pulse width modulation.

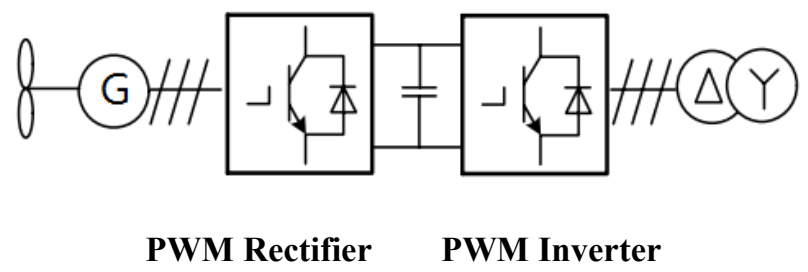

Fig. 1. Grid-connected wind power generation system

Application of AC-DC-AC grid-connected wind power generation system can cover the shortage of synchronous or asynchronous generators. Its' topology is shown in Fig. 1. As can be seen, there are two PWM converters in this 
topology [3].

PWM rectifier on the generator side takes charge of achieving the Maximum Power Point Tracking (MPPT) function of the generator operation. And, PWM inverter on the grid side takes charge of feeding power to the power grid and achieving the power factor correction (PFC) function.

\subsection{System modeling}

The three-phase full-bridge voltage-source PWM rectifier is a widely used topology. It is shown in Fig. 2.

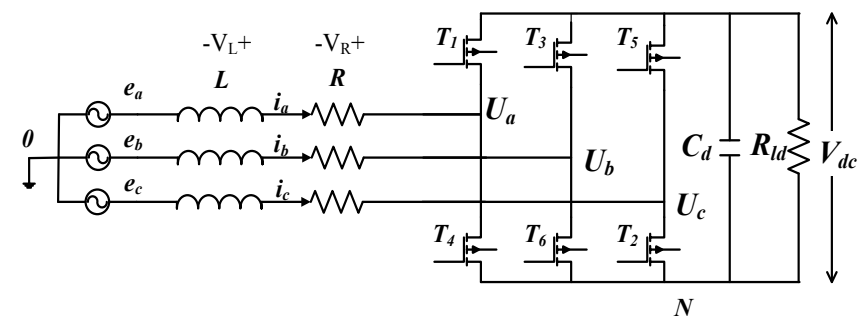

Fig. 2. Three-phase full-bridge PWM rectifier

Let $U_{a}$ be the electric potential between two switching devices of the A-phase bridge arm, $E_{a}$ is be the A-phase voltage source electromotive force, and $U_{a 0}$ refer to the potential difference between point $\mathrm{U}_{\mathrm{a}}$ and point 0 .

Then, $\mathrm{U}_{\mathrm{a} 0}$ can be expressed as follows:

$$
\begin{aligned}
U_{a 0} & =E_{a}+V_{L}+V_{R} \\
& =E_{a}-L \times \frac{d i_{a}}{d t}-R \times i_{a}
\end{aligned}
$$

And, $\mathrm{U}_{\mathrm{a} 0}$ is also

$$
U_{a 0}=U_{a N}+U_{N 0}
$$

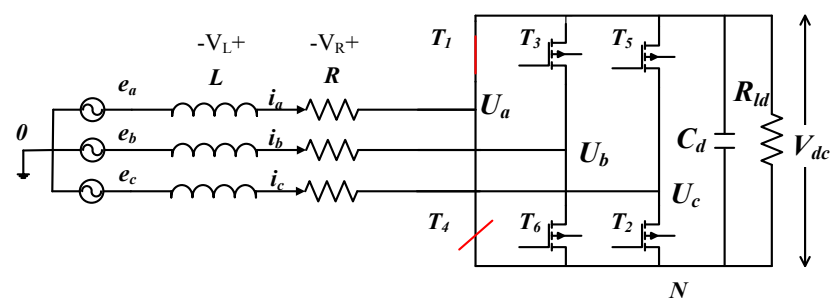

Fig. 3. Operation mode $\left(\mathrm{T}_{1}=1, \mathrm{~T}_{4}=0\right)$

When $\mathrm{T}_{1}=1$ and $\mathrm{T}_{4}=0$,

$$
U_{a N}=V_{d c}
$$

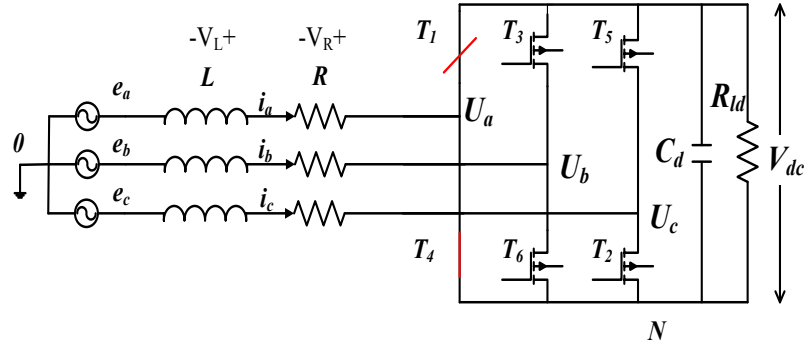

Fig. 4. Operation mode $\left(T_{1}=0, T_{4}=1\right)$

When $\mathrm{T}_{1}=0$ and $\mathrm{T}_{4}=1$,

$$
U_{a N}=0
$$

From (3) and (4), $\mathrm{U}_{\mathrm{aN}}$ can be expressed as

$$
\begin{gathered}
U_{a N}=V_{d c} \times T_{a} \quad\left(\mathrm{~T}_{\mathrm{a}}=T_{1}, T_{1}=1 \text { or } 0\right) \\
U_{k N}=V_{d c} \times T_{k} \quad(k=\mathrm{a}, \mathrm{b}, \mathrm{c})
\end{gathered}
$$

And, the potential difference between $\mathrm{N}$ point $N$ and point $O\left(\mathrm{U}_{N 0}\right)$ is given by (7):

$$
U_{N 0}=-\frac{V_{d c}}{3} \times\left(T_{1}+T_{3}+T_{5}\right)
$$

From equations (1) to (7), we get

$$
\begin{aligned}
U_{k 0} & =E_{k}-L \times \frac{d i_{k}}{d t}-R \times i_{k} \\
& =T_{k} \times V_{d c}-\frac{V_{d c}}{3} \times\left(T_{1}+T_{2}+T_{3}\right) \quad(\mathrm{k}=\mathrm{a}, \mathrm{b}, \mathrm{c})
\end{aligned}
$$

Then, $\mathrm{E}_{\mathrm{k}}$ can be expressed as

$$
E_{k}=L \times \frac{d i_{k}}{d t}+R \times i_{k}+T_{k} \times V_{d c}-\frac{V_{d c}}{3} \times\left(T_{1}+T_{3}+T_{5}\right)
$$

And,

$$
L \times \frac{d i_{k}}{d t}=E_{k}-R \times i_{k}-T_{k} \times V_{d c}+\frac{V_{d c}}{3} \times\left(T_{1}+T_{3}+T_{5}\right)
$$

\subsection{Double loop controller design}

Based on plenty of domestic and foreign literatures [4][6], three-phase PWM rectifier modeling diagram under $\mathrm{d}-\mathrm{q}$ synchronization rotating coordinate system is given by equations (11)-(12) and Fig. 5.

$$
L \times \frac{d i_{q}}{d t}=E_{q}-i_{d} \times R-S_{q} \times V_{d c}-\omega L \times i_{d}
$$




$$
L \times \frac{d i_{d}}{d t}=E_{d}-i_{q} \times R-S_{d} \times V_{d c}-\omega L \times i_{q}
$$

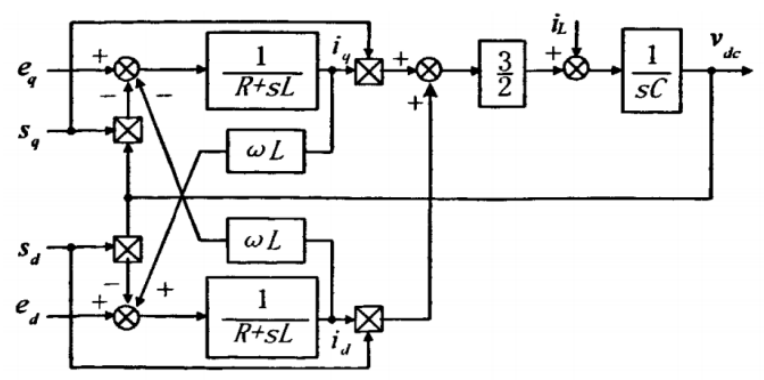

Fig. 5. System modeling under d-q synchronization rotating coordinate system

In Fig. 5, $\mathrm{S}_{\mathrm{d}}, \mathrm{S}_{\mathrm{q}}$ are the switching states; $\mathrm{i}_{\mathrm{d}}, \mathrm{i}_{\mathrm{q}}$ are the input currents; $E_{d}, E_{q}$ are the generating voltages; $i_{L}$ is the load current; and $\omega$ is the angular frequency of the $\mathrm{AC}$ side voltage. They are all under the d-q coordinate system.

According to the control method that is proposed, the above block diagram of the control system can be described as shown in Fig. 6. For traditional topology, we need to know the values "Ea, Eb, Ec" to calculate "Ed, Eq", and "Ia, $\mathrm{Ib}$, Ic" to calculate "Id, Iq". But, since the sensorless scheme was used, the three voltage sensors can be abandoned, and we can estimate "Ed, Eq" with only "Ia, Ib, Ic and Vdc".

The control system includes two PI controllers. AC currents are controlled by the inner PI controller so that the currents flow in-phase with the AC side voltage. In Fig. 6, $\phi_{\mathrm{v}}$ is the phase position of the three-phase voltage, $\phi_{\mathrm{i}}$ is the phase position of the three-phase current, and the deviation between them is $\phi_{\text {error }}$. If $\phi_{\text {error }}$ is greater than 0 , that means the phase of the input voltage is leading the input current phase. If $\phi_{\text {error }}$ is less than 0 , that means the phase of the input voltage is lagging the input current phase.

The PI controller was able to correct the vector rotating speed " $\phi_{\Delta}$ " in SVPWM all the way until $\phi_{\text {error was equal to }}$ 0 . When $\phi_{\text {error }}$ is equal to 0 , the input power factor is 1 . Also, the output DC voltage $\mathrm{V}_{\mathrm{dc}}$ is controlled by the outer PI controller output $M$, which is the SVPWM modulation index.

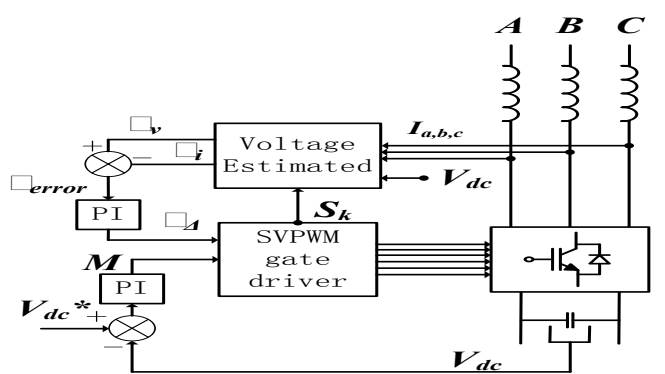

Fig. 6. Block diagram of control system
In addition, the current control in synchronous frame has an advantage since it is able to minimize the steady-state error. In this work, current control with PI compensator that operates in synchronous frame is employed. The DC-link voltage control loop with PI compensator is used to regulate the DC output voltage.

\subsection{SVPWM switching method}

Fig. 7 shows a space voltage vector diagram for threephase PWM rectifier. As an example, let a reference voltage vector $\left(\mathrm{V}^{*}\right)$ be located in section I. In this case, the effective voltage vectors of $V_{1}$ and $V_{2}$ are used for switching [7]. The quantity $\phi_{\Delta}$ in Fig. 6 determines the rotating speed of $\mathrm{V}^{*}$, and $M$ determines the length of $\mathrm{V}^{*}$. The fundamental rotating speed of $\mathrm{V}^{*}$ was set as $60 \mathrm{~Hz}$. The speed can be adjusted by " $\phi_{\Delta}$ " when voltage and current are not in-phase

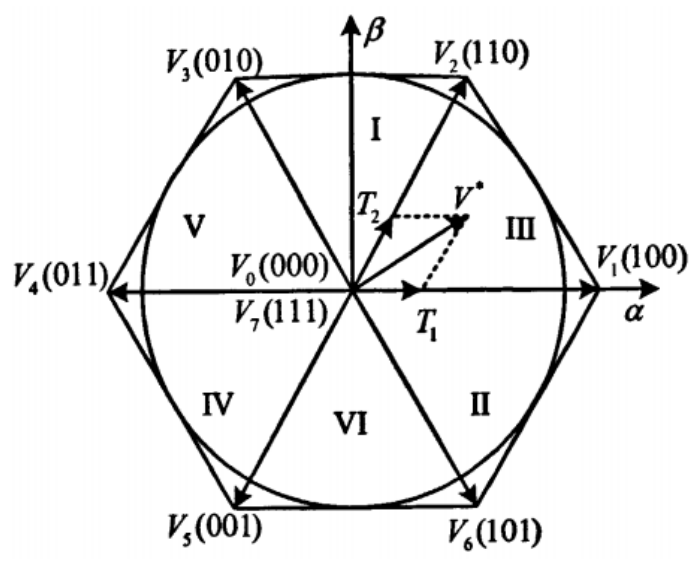

Fig. 7. Location and synthesis of space voltage vectors

\section{Simulation Results}

To confirm the validity of the proposed method, PSIM simulation is performed. The simulation parameters are given in Table 1.

Table 1. Nominal system parameters

\begin{tabular}{|c|c|}
\hline Parameter & Value \\
\hline $\mathrm{E}_{\mathrm{a}, \mathrm{b}, \mathrm{c}}$ & $400 \mathrm{~V}_{\mathrm{p}-\mathrm{p}} / 200 \mathrm{~V}_{\mathrm{p}-\mathrm{p}}$ \\
\hline $\mathrm{L}_{\mathrm{a}, \mathrm{b}, \mathrm{c}}$ & $1000 \mu \mathrm{H}$ \\
\hline $\mathrm{R}_{\mathrm{a}, \mathrm{b}, \mathrm{c}}$ & $0.5 \Omega$ \\
\hline $\mathrm{fsw}_{\mathrm{sw}}$ & $20 \mathrm{kHz}$ \\
\hline $\mathrm{C}_{\mathrm{d}}$ & $1000 \mu \mathrm{F}$ \\
\hline $\mathrm{R}_{\mathrm{ld}}$ & $50 \Omega$ \\
\hline
\end{tabular}

Fig. 8 shows the AC-side voltage phase angle and inductor current phase angle under $\mathrm{d}-\mathrm{q}$ synchronization rotating coordinate system. 


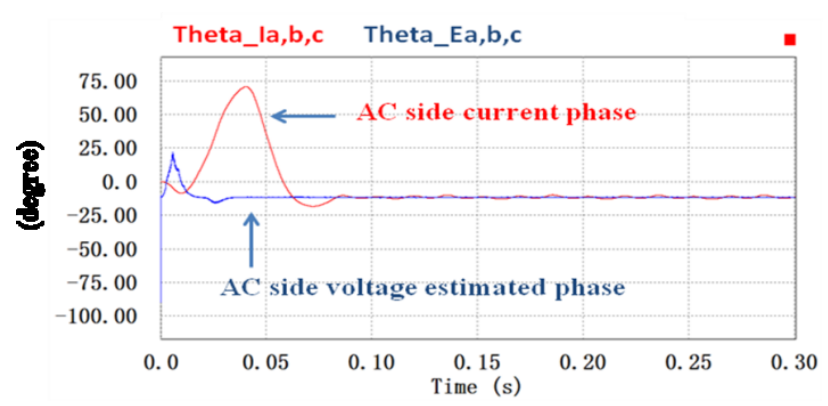

Fig. 8. AC-side voltage and current phase angles

As can be seen, the current vector phase angle has the ability to track the input AC voltage vector phase angle. That means the power factor will finally track to unity power factor.

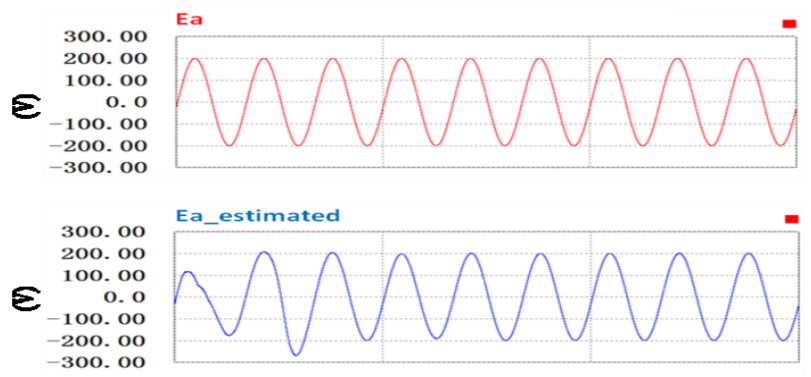

Fig. 9. Phase voltage $\left(E_{a}\right)$ waveform of input $A C$ side and its estimated result ( $\left.E_{\mathrm{a} \_ \text {estimated }}\right)$

In Fig. 9 and 10, $\mathrm{E}_{\mathrm{a}}$ is input $\mathrm{AC}$ voltage (generator side) waveform of A-phase. $\mathrm{E}_{\mathrm{a}_{\text {_estimated }}}$ refers to the estimated result found by equation (9). If the system error is ignored, they are almost the same.

So, we can abandon the AC-side voltage sensors and, instead, utilize the estimated results to calculate the AC-side voltage vector phase.

According to equation (9), calculation of $E_{a}$ estimated requires the $\mathrm{V}_{\mathrm{dc}}$ voltage value. But, the sampling and filtering delay led to errors in the estimation. This phenomenon only existed in the first $0.05 \mathrm{sec}$, when the DC-link voltage was changing.

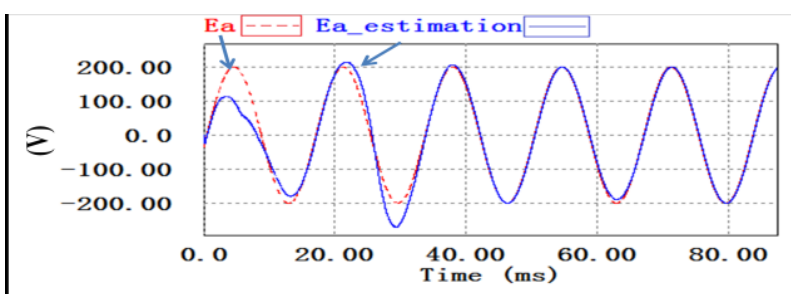

Fig. 10. Enlarged waveforms of $E_{a}$ and $E_{a}$ estimated from Fig. 9.

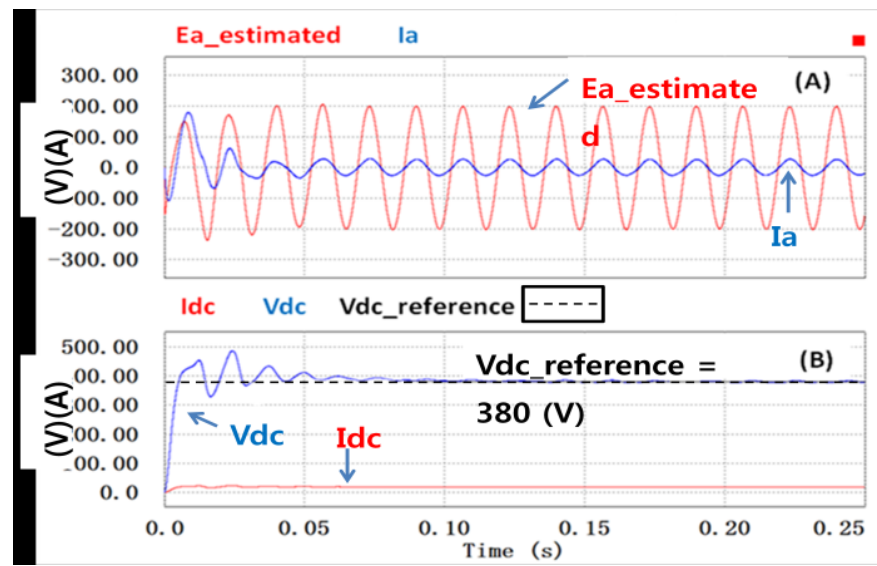

Fig. 11. Steady state characteristics (a) AC-side estimated voltage ( $\left.\mathrm{E}_{\mathrm{a} \text { _estimated }}\right)$ of A-phase (b) DC-link voltage reference $\left(\mathrm{V}_{\mathrm{dc} \_ \text {reference }}\right)$, DC-link voltage $\left(\mathrm{V}_{\mathrm{dc}}\right)$, and load current $\left(\mathrm{I}_{\mathrm{dc}}\right)$

Fig. 11(a) shows the estimated AC-side phase voltage waveform and its current waveform. As can be seen, they are in phase with each other and the current waveform is almost a pure sinusoidal waveform. Fig. 11(b) shows the DC-side voltage waveform and its desired value, which is $380 \mathrm{~V}$. With use of the estimated quantities for the feedback control, the control performance is still satisfactory.

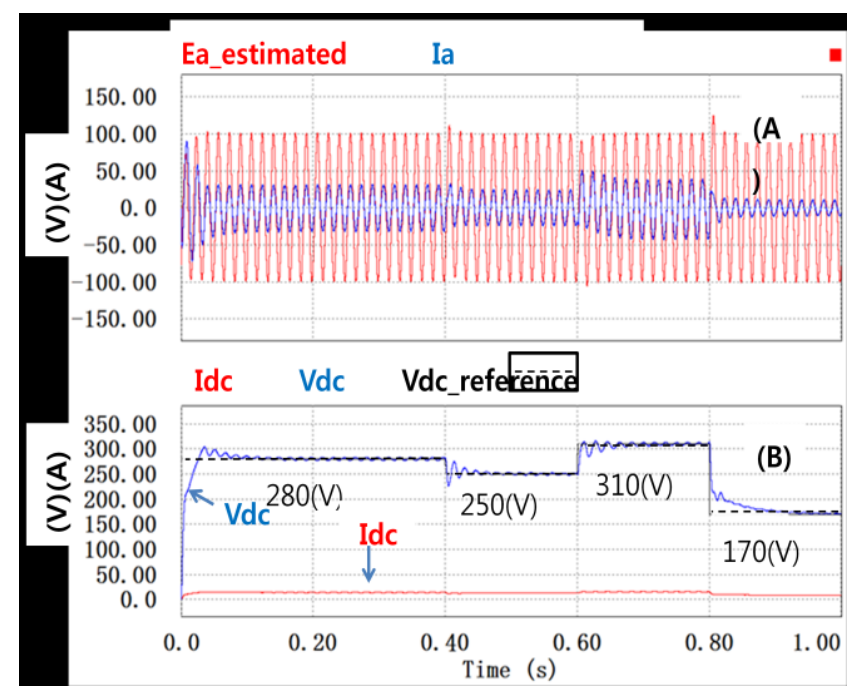

Fig. 12. Dynamic response characteristics for the different DC reference voltages

Fig. 12 shows the transient state response for the different DC voltage references. The desired DC voltage value changed from $280 \mathrm{~V}-250 \mathrm{~V}-310 \mathrm{~V}-170 \mathrm{~V}$. Because of the outer loop PI controller, the output DC voltage has the ability to track the reference value within a fast setting time and with little oscillation. 


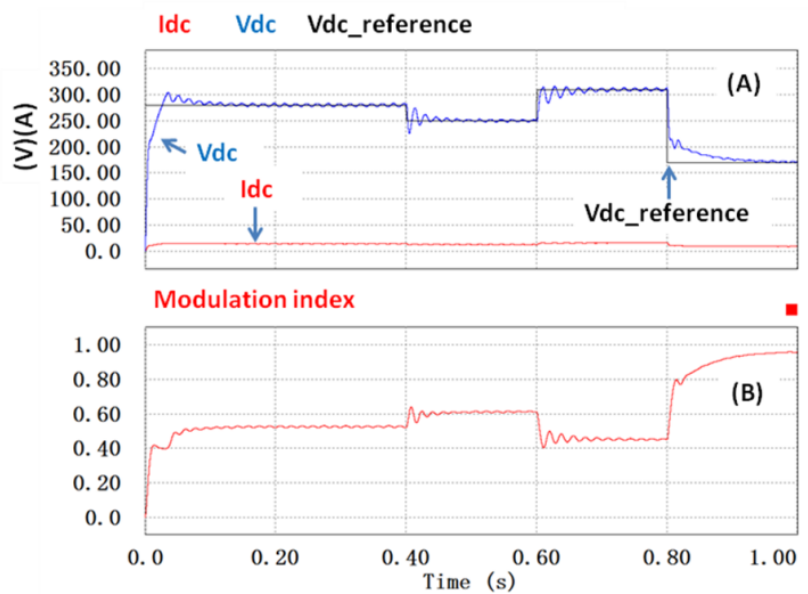

Fig. 13. (a) DC-link voltage, load current (b) SVPWM modulation index for DC-link voltage references

Fig. 13 shows the dynamic behavior of SVM modulation index $M$ while the desired DC voltage reference value was changing. Modulation index varied from 0.5 to 1.0 as the DC desired value varied from $170 \mathrm{~V}$ to $310 \mathrm{~V}$.

\section{Conclusion}

In this paper, a control scheme for the three-phase PWM rectifier in a wind power generation system without input AC voltage (generator side) sensors was proposed. The computer simulations proved the feasibility of this method. However, this kind of voltage sensorless control method needs a fast sampling frequency and high-performance operator in order to calculate the differential value of the inductor currents.

\section{References}

[1] A. W. Green, J. T. Boys, and G. F. Gates. "Three-phase voltage sourced reversible rectifier," IEE. Proc. Electric Power Appl., vol. 135, no. 6, pp. 362-370, 1988.

[2] B. T. Ooi, et al., "A three-phase controlled-current PWM converter with leading power factor," IEEE Trans. Ind. Appl., vol. IA-23, pp. 78-84, 1987.

[3] V. Blasko and V. Kaura, "A new mathematical model and control of a three-phase AC-DC voltage source converter," IEEE Trans. Power Electron., vol. 12, no.1, pp. 116-123, 1997.

[4] J. J. Shied, C. T. Pan, and Z. J. Cuey, "Modeling and design of a reversible three-phase switching mode rectifier", IEE. Proc. Electric Power Appl., vol. 144, no. 6, pp. 389396, 1997.

[5] T. Noguchi, et al., "Direct power control of PWM converter without power-source voltage sensors," in Proc. IEEE IAS'96, 1996, pp. 941-946.

[6] R. Wu, et al., "Analysis of an AC to DC voltage source converter using PWM with phase and amplitude control," in Conf. Rec. of IEEE IAS'89, 1989, pp. 1156-1163.
[7] R. Wu, et al., "Analysis of a PWM AC to DC voltage source converter under the predicted current control with a fixed switching frequency," IEEE Trans. Ind. Appl., vol. 27, no. 4, pp. 756-764, 1991.

[8] Sudip Mazumder, Ali H. Nayfeh, and Dushan Borojevic, "New sensorless control of three-phase bi-directional converter using space-vector modulation," in Conf. Rec. of IEEE PESC'99, 1999, pp. 783-788.

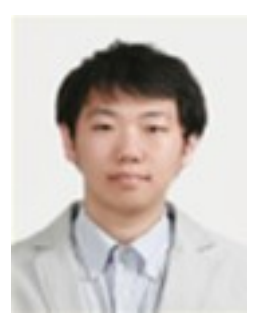

YanJun Wu received his B.S. degree in Electronic Information Technology in 2009 from Shanghai University of Engineering, China. He entered the College of Electrical Engineering in Chonnam National University, Korea, to study toward the Master's degree. His current research interests include Z-source inverters, motor drivers, and PWM rectifiers. 